\title{
Mesenchymal stem cell transformation and sarcoma genesis
}

\author{
Wei Xiao, Alexander B Mohseny, Pancras C W Hogendoorn and Anne-Marie Cleton-Jansen*
}

\begin{abstract}
MSCs are hypothesized to potentially give rise to sarcomas after transformation and therefore serve as a good model to study sarcomagenesis. Both spontaneous and induced transformation of MSCs have been reported, however, spontaneous transformation has only been convincingly shown in mouse MSCs while induced transformation has been demonstrated in both mouse and human MSCs. Transformed MSCs of both species can give rise to pleomorphic sarcomas after transplantation into mice, indicating the potential MSC origin of so-called non-translocation induced sarcomas. Comparison of expression profiles and differentiation capacities between MSCs and sarcoma cells further supports this. Deregulation of P53- Retinoblastoma-, PI3K-AKT-and MAPK pathways has been implicated in transformation of MSCS. MSCs have also been indicated as cell of origin in several types of chromosomal translocation associated sarcomas. In mouse models the generated sarcoma type depends on amongst others the tissue origin of the MSCs, the targeted pathways and genes and the differentiation commitment status of MSCs. While some insights are glowing, it is clear that more studies are needed to thoroughly understand the molecular mechanism of sarcomagenesis from MSCs and mechanisms determining the sarcoma type, which will potentially give directions for targeted therapies.
\end{abstract}

Keywords: MSC, Sarcoma, Bone tumour, Soft tissue tumour, Osteosarcoma, Ewing sarcoma

\section{Introduction}

MSCs have been under intensive research and application efforts since their first establishment by Friedenstein and his colleagues in 1968 [1]. Standard criteria developed by the International Society for Cellular Therapy define MSCs by three characteristics: 1) plastic adherence under standard culture conditions, 2) expression of CD105, CD73 and CD90 and no expression of CD45, CD34, CD14, CD11b, CD79b, CD19 and HLA-DR and 3) capacity to differentiate into osteoblasts, chondroblasts and adipocytes in vitro, termed trilineage differentiation potential (Figure 1) [2].

Owing to the ease of isolation, expansion, the multilineage differentiation potential and a variety of physiological functions, MSCs are applied in a wide range of experimental and medical applications. Among them are the enhancement of hematopoietic stem cell engraftment, the amelioration of acute graft-versus-host disease, cardiac

\footnotetext{
* Correspondence: A.M.Cleton-Jansen@lumc.nl
Department of Pathology, Leiden University Medical Center, Albinusdreef 2,

* Correspondence: A.M.Cleton-Jansen@lumc.nl
Department of Pathology, Leiden University Medical Center, Albinusdreef 2, 2333ZA, Leiden, the Netherlands
}

diseases and regenerative medicine approaches for especially bone and cartilage [2].

Cell transformation is a process during which genetic changes occur, resulting in cells with the ability to grow indefinitely and anchorage-independently and with tumorigenic properties upon transplantation [3-7]. Senescence has been overcome in these transformed cells $[4,8-10]$. On one hand, the potentials of MSCs to transform, to initiate sarcomas and under some conditions to facilitate tumour progression are calling for caution for MSC-based applications [5,11]. On the other hand, the transforming property of MSCs and their possible role as sarcoma progenitors make these cells useful for studying sarcomagenesis and progression. In this review we present an overview of the roles of MSCs in sarcomas, with a specific focus on tumorigenic transformation and sarcomagenesis.

\section{MSC transformation}

\section{Spontaneous mouse MSC transformation}

Mouse MSCs have been consistently demonstrated to spontaneously undergo tumorigenic transformation after long term ex vivo culture $[4,6]$. This transformation
C Biomed Central

(c) 2013 Xiao et al.; licensee BioMed Central Ltd. This is an Open Access article distributed under the terms of the Creative Commons Attribution License (http://creativecommons.org/licenses/by/2.0), which permits unrestricted use, distribution, and reproduction in any medium, provided the original work is properly cited. 


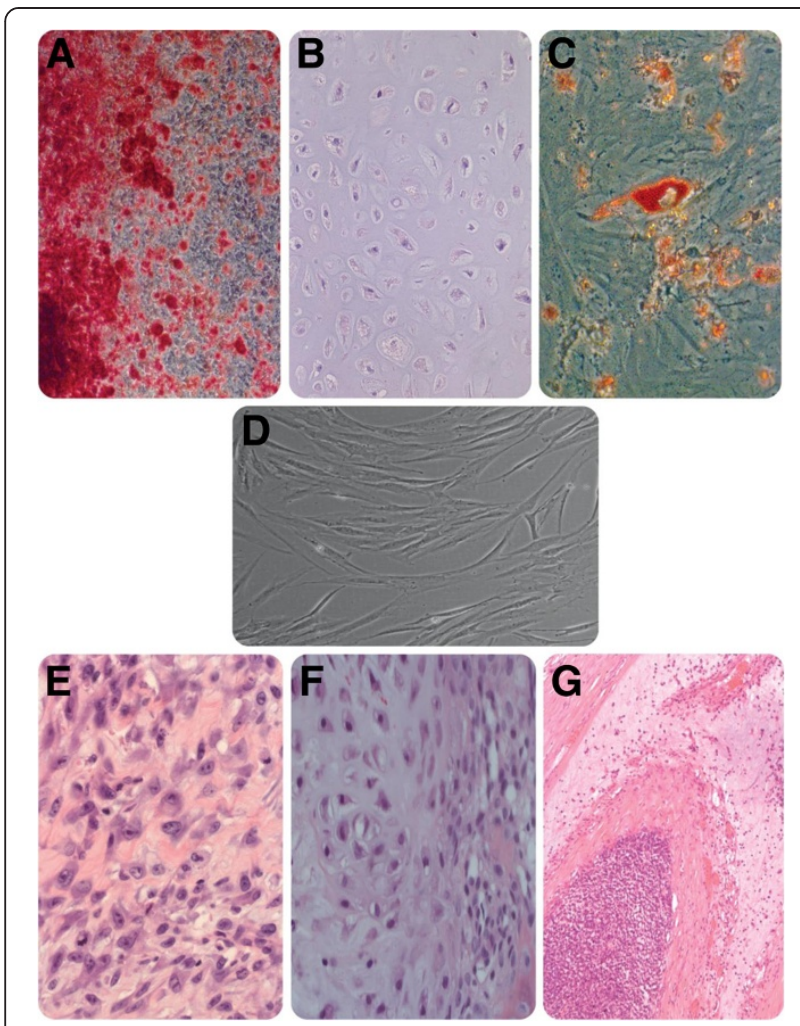

Figure 1 Trilineage differentiation capacity of human MSCs and representative types of sarcomas. Human MSCs are capable of differentiating into osteoblasts, chondrocytes and adipocytes under proper inductions. This differentiation spectrum corresponds with the histological spectrum of different types of sarcomas, represented here by osteosarcoma, chondrosarcoma and liposarcoma. This correlation supports the hypothesis that MSCs are the cell of origin of sarcomas. A: alizarin red staining for osteoblast differentiation assay, B: toluidine blue staining for chondrocyte differentiation assay of MSC pellets, C: oil red staining for adipocyte differentiation.

D: human MSC cell culture. E: osteosarcoma, F: chondrosarcoma, G: liposarcoma.

process can also be induced by certain manipulations, including both gene targeting and drug or chemical treatment to affect crucial pathways (Table 1) [11-14]. In contrast, human MSCs do not spontaneously transform in vitro, even after long term culturing, which will be discussed later in more detail $[9,13,15]$.
Mouse MCSs are reported to spontaneously undergo changes in morphology, proliferation rate, migration ability, cell surface marker profile, genomic constitution and most importantly tumorigenicity after long term in vitro culture $[4,9,20,21]$. Meanwhile, one study has also revealed that mMSCs could transform even after short term in vitro culture. Injection of passage 3 mMSCs into mice resulted in formation of tumours comparable with soft tissue sarcomas [19]. Transformed mouse MSCs always show a higher proliferation rate than the native cells [3,4]. These transformed cells exhibit tumorigenicity, as shown by anchorage-independent growth assay and xeno-transplantation in mice and zebrafish, while this is not observed with low passage mouse MSCs before their transformation [3,4,6,22]. Interestingly, the readiness of in vitro tumorigenic transformation seems to be a unique property of mouse MSCs since it is absent in most other mouse stem cells, including hematopoietic stem cells and embryonic stem cells [23]. This readiness can be probably ascribed to the genetic instability already shown in mouse MSCs very shortly after isolation from bone marrow, although the cytogenetic abnormalities in low passage mouse MSCs are considerably less in number than in transformed mouse MSCs [23]. Interestingly, MSC spontaneous transformation happens much less frequently in vivo, as shown by the low incidence of spontaneous sarcomagenesis in mice. This can be possibly explained by the different microenvironment of in vitro and in vivo conditions for MSCs. Solid research on the role of the in vivo niche of BMMSCs in guarding its genomic stability is needed to answer this question more exactly.

\section{Induced mouse MSC transformation}

Transformation of mouse MSCs has been induced by an array of manipulations, including knockout of tumour suppressor genes, overexpression of oncogenes and drug administration to affect signaling pathways. The pathways targeted by these manipulations are mostly involved in cell cycle checkpoint control, cell survival, proliferation and apoptosis (Table 2) [14]. In one study, loss of tumour suppressor $P 21$ and $T p 53$ in mouse adipose derived MSCs (AMSC) induced in vitro transformation

Table 1 A summary of spontaneous transformation studies with mouse BMMSCs

\begin{tabular}{|c|c|c|c|}
\hline Transformation after & Type of sarcoma & Associated genetic event(s) & Reference \\
\hline & Osteosarcoma & Aneuploidy + CDKN2A/p16 loss & [4] \\
\hline & & Abnormal karyotype & {$[6]$} \\
\hline \multirow[t]{3}{*}{ Long term culture } & Fibrosarcoma & p53 mutations & {$[24]$} \\
\hline & & Chromosomal instability + TERT and c-myc expression & {$[16]$} \\
\hline & Undiff. soft tissue sarcomas & Aneuploidy + chromosomal translocations & {$[17]$} \\
\hline Short term culture & Soft tissue sarcomas & Aneuploidy & {$[18]$} \\
\hline
\end{tabular}


Table 2 A summary of induced transformation studies with mouse cells

\begin{tabular}{|c|c|c|c|c|}
\hline \multicolumn{5}{|c|}{ Sarcomas without specific chromosomal translocation } \\
\hline Cell type & $\begin{array}{l}\text { Inactivated } \\
\text { gene(s) }\end{array}$ & $\begin{array}{l}\text { Expressed } \\
\text { gene(s)/treatment }\end{array}$ & Type of sarcoma & Reference \\
\hline \multirow[t]{2}{*}{ mASCs } & $\mathrm{p} 21+\mathrm{p} 53$ & - & "Fibrosarcoma" & [20] \\
\hline & $\mathrm{p} 53$ or $\mathrm{p} 53+\mathrm{Rb}$ & - & Leiomyosarcoma & [7] \\
\hline BM-mMSCs & INK4A/ARF & c-myc & Osteosarcoma & [24] \\
\hline Osteoblastic lineage & $\mathrm{p} 53$ or $\mathrm{p} 53+\mathrm{Rb}$ & - & Osteosarcoma & {$[32,33]$} \\
\hline \multirow[t]{2}{*}{ Mesenchymal cells of limb buds } & p53 & - & Osteosarcoma & [23] \\
\hline & $\mathrm{p} 53+\mathrm{Rb}$ & - & Undifferentiated sarcoma & [23] \\
\hline Muscle, uterus & p53 orlNK4AVARF & K-RAS & High-grade sarcoma with myofibroblastic differentiation & [25] \\
\hline Muscle & p53 & K-RAS & Pleomorphic rhabdomyosarcoma & [18] \\
\hline Smooth muscle lineage & PTEN & - & Leiomyosarcoma & [17] \\
\hline MSC progenitors & APC & - & Aggressive fibromatosis & [67] \\
\hline \multicolumn{5}{|c|}{ Sarcomas with specific chromosomal translocation } \\
\hline Cell type & \multicolumn{2}{|c|}{ Expressed fusion gene } & Type of sarcoma & Reference \\
\hline \multirow[t]{4}{*}{ BM-mMSCs } & \multicolumn{2}{|l|}{ EWS-FLI-1 } & Ewing sarcoma & [63] \\
\hline & \multicolumn{2}{|l|}{ EWS-FLI-1 } & Ewing sarcoma & [65] \\
\hline & \multicolumn{2}{|l|}{ FUS-CHOP } & Myxoid liposarcoma & [11] \\
\hline & \multicolumn{2}{|l|}{ PAX3/7-FKHR } & Alveolar rhabdomyosarcoma & [71] \\
\hline mASCs & \multicolumn{2}{|l|}{ FUS- CHOP } & Liposarcoma & [11] \\
\hline Mesenchymal cells of limb buds & \multicolumn{2}{|l|}{ EWS-FLI-1 } & Ewing sarcoma & {$[65]$} \\
\hline $\begin{array}{l}\text { Differentiated muscle cells } \\
\text { (MYF6-expressing cells) }\end{array}$ & \multicolumn{2}{|l|}{ PAX3-FKHR } & Liposarcoma & [70] \\
\hline
\end{tabular}

and in vivo so-called fibrosarcoma formation after transplantation [24]. In another study, both Tp53-/- Rb-/and Tp53-/- mouse AMSCs were generated through Cre mediated excision of loxP flanked loci. Leiomyosarcomalike tumours were developed in the in vivo tumorigenicity assays of these 2 types of mouse AMSCs [8]. The combination of $C d k n 2 a$ loss and $C-m y c$ overexpression in mouse BMMSCs gave rise to osteosarcomas accompanied by the loss of adipogenic differentiation capacity in transformed mouse BMMSCs [16]. Besides directly targeting in vitro cultured MSCs, several genetically engineered mouse models have been developed to investigate the effects of genes on transformation process. A conditional mouse model with Tp53 homozygous deletion has been created by crossing Prx1-Cre transgenic mice to mice bearing alleles of Tp53 flanked by loxP. Prx1 is specifically expressed in the early mesenchymal tissues of embryonic limb buds [17]. In these P53deficient mice many types of sarcomas occurred in the mesenchymal cells of limb buds and osteosarcoma was the most common type. A mouse model with loss of RB generated also through Cre-loxP system was not found to display tumorigenesis. However, loss of RB accelerated tumorigenesis in P53-deficient mice [17]. These induced transformation studies established the importance of the P53 pathway in preventing mouse MSC transformation.
Besides, in spontaneous transformation studies of mouse MSCs, defects in Tp53 or Cdkn2a genes were frequently found [18]. P53 and P14, proteins encoded by these two genes, are both important members of P53 pathway, further corroborating the crucial role of P53 pathway in mouse MSC transformation [4,25]. Upregulated oncogenic pathways have also been shown to induce or potentiate mouse MSC transformation. Fos is an oncogene encoding a transcription factor downstream of many growth factor pathways. The Fos overexpression transgenic mice resulted in the development of bone tumours, with chondrosarcomas as the main type [26]. This is puzzling as the driver mutation in human central chondrosarcoma is IDH1 or IDH2 [27], while in peripheral chondrosarcomas this is not known $[27,28]$, but no indication for involvement of Fos is found $[28,29]$. The PI3K-AKT pathway is crucially involved in apoptosis and proliferation. In a study a mouse model with homozygous loss of Pten, a negative regulator of the PI3K-AKT pathway in smooth muscle lineage cells developed leiomyosarcomas [30,31]. The MAPK pathway is principally responsible for mitosis. Overexpression of $K$-ras, a component of the MARK pathway in addition to P53 loss induced sarcoma formation in mice more efficiently than in mice with P53 loss alone [32,33]. These studies underscore the 
role of different oncogenic pathways to promote mouse MSC transformation.

\section{Human MSC transformation}

Human MSCs have not been shown to undergo spontaneous transformation in vitro $[9,15,43]$. There have been few reports on spontaneous human MSC in vitro transformation, of which two turned out to be caused by contamination by tumour cell lines and were retracted afterwards $[34,35,44]$. Meanwhile, there are several studies demonstrating that human MSCs did not go through transformation in spite of long term in vitro culturing $[12,15]$. For the possibility of in vivo spontaneous transformation, there have been few cases of osteosarcoma genesis in patients infused with bone marrow MSCs for other diseases [45-47]. The majority studies of human MSC transformation are based on genetic approaches to knock out important tumour suppressor genes and overexpress certain oncogenes Table 3) [14]. In contrast to mouse MSC studies, four of the induced human MSC transformation studies consist of the exogenous expression of hTERT in human cells [38,48-50]. This may be attributed to the much shorter telomeres in human MSCs than their mouse counterparts, the much shorter life span of mice than human and the difference in telomere damage signaling pathways between mouse and human $[41,50,51]$. Consistent with mouse MSC studies, the disruption of cell cycle control machineries, exemplified by P53 and RB pathways are also important for human MSC transformation. For instance, the introduction of SV40-LT, which perturbs both P53 and RB proteins potently promoted human MSC transformation [38]. Furthermore, the overexpression of some oncogenes has also been shown to contribute to the transformation, such as $H$-RAS [5-7]. Although the definite spontaneous transformation capacity of mouse MSCs is not a mimicry of human MSCs, the signaling pathways underlying their tumorigenic transformation show high consistency, including the P53 pathway, RB pathway, PI3K-AKT pathway and MAPK pathway and so on.

\section{MSCs as the origin of sarcomas and tumour type specificity}

There is substantial evidence supporting a MSC origin of a spectrum of sarcomas, both pleomorphic as well as translocation driven subtypes. In the non-translocation -driven sarcoma types, the correspondence between the differentiation capacity of MSCs and the histological spectrum of different types of sarcomas is reflected (Figure 1). Approaches and methods have also been used to investigate this hypothesis, including differentiation assays, expression profiling and Immunohistochemistry [52-54]. Based on the site of presentation, sarcomas can be categorized into bone tumours and soft tissue tumours. Based on genetic profiles, sarcomas can be categorized into two groups, one with relatively simple genetic alterations, either being associated with point mutations or reciprocal translocations, and the other with extensive genetic changes. Examples of the cytogenetically relatively simple group are alveolar rhabdomyosarcoma, myxoid liposarcoma, Ewing sarcoma and synovial sarcoma. Examples of the other group are leiomyosarcoma, undifferentiated pleomorphic sarcoma and osteosarcoma [55].

MSC differentiation towards a defined and differentiated cell type is a process with a lot of different signaling pathways and differentiation stages involved (Figure 2). The sarcoma type arising from in vitro transformed MSCs after inoculation into mice seems to be dependent on many factors, including the originating tissue of the MSCs, the differentiation commitment status of the targeted cell and also the targeted molecular pathways. In most cases with bone marrow derived mouse MSCs (BMMSC) or osteochondro progenitors osteosarcomalike tumours were formed. With AMSCs or smooth muscle cell progenitors leiomyosarcomas were mostly formed (Table 4) $[8,16,24]$. BMMSCs from aged mice tend to spontaneously give rise to so-called fibrosarcomas instead of osteosarcomas as in most spontaneous transformation studies [25]. It must be added that according to the present view fibrosarcomas is a poorly defined histological entity. It is necessary to perform large scale studies to specifically address the relationship between tissue origin, targeted pathways and the sarcoma type generated, which is currently lacking.

\section{Bone sarcomas}

\section{Ewing sarcoma}

Ewing sarcoma arises predominantly in bone but in soft tissues as well. It is a type of a poorly differentiated tumour known to be associated with a the expression of

Table 3 A summary of human BMMSCs transformation without specific chromosomal translocation

\begin{tabular}{lll}
\hline Type of sarcomas & Expressed gene(s)/treatment & Reference \\
\hline & hTERT + HPV16 E6/E7 + SV40-ST + H-RAS & {$[44]$} \\
Undifferentiated spindle cell sarcoma & hTERT + SV40-LT + H-RAS & {$[13]$} \\
& hTERT + H-RAS + BMI-1 & {$[43]$} \\
Tumors with smooth muscle and bone properties & hTERT4 & [33] \\
Undifferentiated pleomorphic sarcomas & DKK1 + SV40-LT & {$[14]$} \\
\hline
\end{tabular}




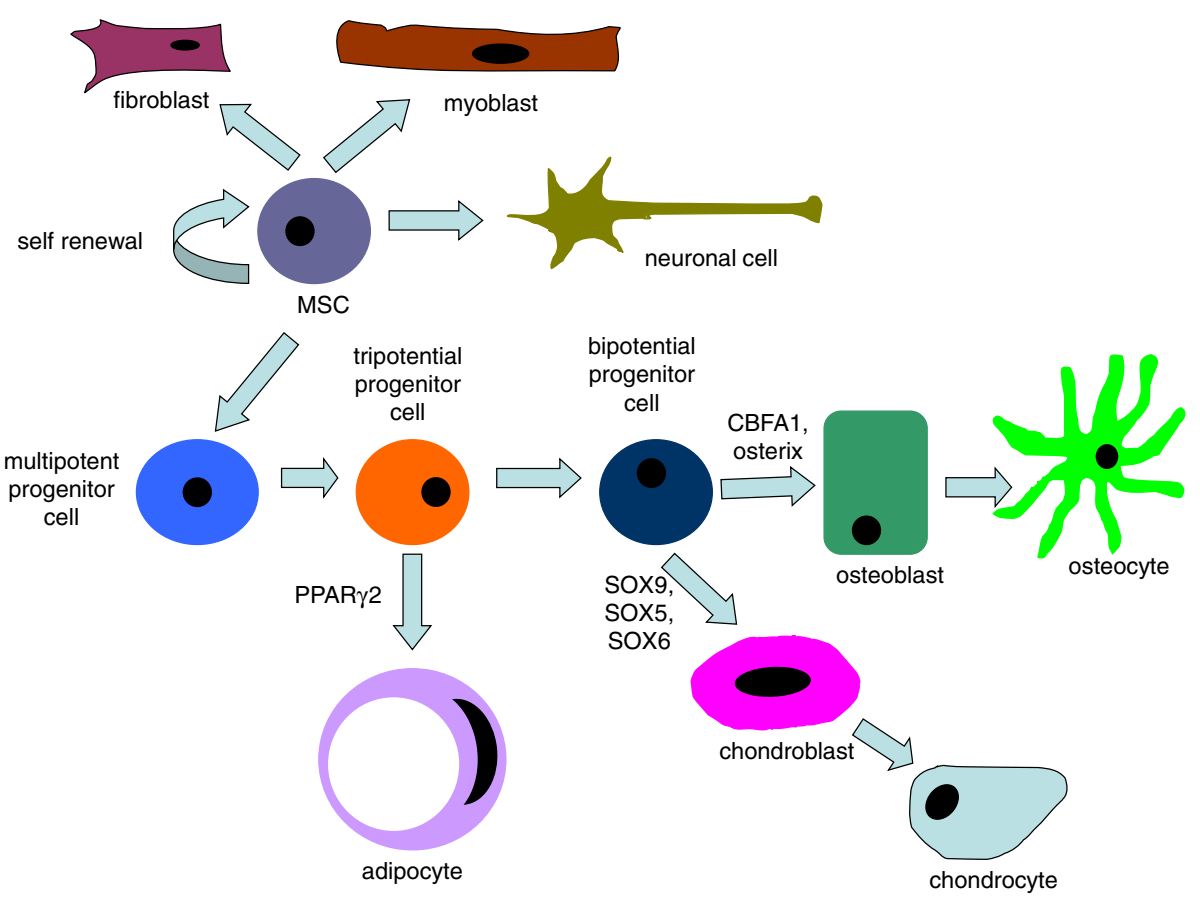

Figure 2 MSC differentiation scheme. Under different signaling regulations, MSCs can differentiate into different types of cells. The differentiation process involves sequential signaling regulation and many different stages.

EWSR1-ETS fusions or rarely other chimeras [59-62]. The exogenous expression of the fusion gene EWS-FLI1 alone in mouse MSCs has been shown to transform these cells, demonstrated by in vitro immortalization and in vivo sarcomatous tumour formation after inoculation in immunocompetent mice [63]. In another study a secondary genetic alteration was needed for the induced transformation of mouse MSCs [64]. Similar manipulations have been also applied on human MSCs. Human MSCs with exogenous EWS-FLI1 expression transformed and these transformed cells expressed neuroectodermal markers [65]. Moreover, the knockdown of EWS-FLI1 expression in Ewing sarcoma cell lines restored the in vitro trilineage differentiation ability of the cells [52]. In a

Table 4 A summary of sarcoma types from different transformation studies in mice

\begin{tabular}{|c|c|c|c|}
\hline Sarcoma type & Cell of origin & Targeted genes & Reference \\
\hline \multirow{7}{*}{ Osteosarcoma } & \multirow[t]{3}{*}{ Mouse BMMSCs } & - & {$[4]$} \\
\hline & & - & {$[6]$} \\
\hline & & C-myc overexpression and Ink4a/Arf knockout & {$[16]$} \\
\hline & Mouse osteoblast precursors & Tp53, Rb double knockout & {$[56]$} \\
\hline & \multirow[t]{3}{*}{ Mouse osteoblasts } & Tp53knockout & {$[57]$} \\
\hline & & Tp53 and $R b$ double knockout [57] & \\
\hline & & Tp53 knockout & {$[17]$} \\
\hline \multirow{4}{*}{ Leiomyosarcomas } & \multirow[t]{3}{*}{ Mouse AMSCs } & Tp53 knockout & {$[14]$} \\
\hline & & Tp53 knockout & {$[24]$} \\
\hline & & Tp53 and $R b$ double knockout [8] & \\
\hline & Mouse smooth muscle lineage cells & Pten knockout & {$[30]$} \\
\hline \multirow{3}{*}{ "Fibrosarcoma" } & Mouse BMMSCs & - & {$[58]$} \\
\hline & Aged mouse BMMSCs & - & {$[25]$} \\
\hline & Mouse AMSCs & P21 knockout, Tp53 heterozygous knockout & {$[24]$} \\
\hline \multirow{2}{*}{ Pleomorphic rhabdomyosarcoma } & Mouse skeletal muscle cells & K-ras overexpression and Tp53 knockout & {$[32]$} \\
\hline & & K- ras overexpression and Tp53 heterozygous knockout [32] & \\
\hline
\end{tabular}


transgenic mouse model, by expressing EWS-FLI1 gene specifically in the mesoderm-originated tissues in limbs and simultaneous Tp53 knockout, sarcomas with similar characteristics as Ewing sarcoma occurred while with only Tp53 knockout the primary sarcoma type was osteosarcoma [66]. In brief, Ewing sarcoma, originally considered as tumours arising from the neuroectodermal lineage and not considered of mesenchymal origin could be experimentally derived directly from MSCs, but only upon introducing the typical translocation. This strongly supports an MSC origin of Ewing sarcoma [67].

\section{Osteosarcoma}

Osteosarcoma is the most common primary malignant bone tumour among children. It is characterized by the production of osteoid and extensive cytogenetic instability [36]. Different studies have supported the MSC origin of osteosarcoma [4,16]. Both spontaneous and induced MSC models for osteosarcoma have been discussed above. Osteosarcomas mainly arise in the metaphyses of long bones and the peak incidence is in the second decade of human life, correlating with the rapid bone growth during puberty, a process in which MSCs are crucially involved [37]. In both human osteosarcoma cells and transformed MSCs, frequent aberrations in genes encoding components of P53 pathway have been identified $[4,39]$. In Tp53 knockout mice many types of sarcomas developed and osteosarcoma was the main type [17].

\section{Chondrosarcoma}

A study compared the gene expression profiles of chondrosarcomas of different differentiation degree [53]. Less differentiated chondrosarcomas were shown to have more similarity with MSCs of pre-chondrogenic stages and more differentiated chondrosarcomas share more similarity with fully differentiated chondrocytes. This suggests that chondrosarcoma progression probably parallels deregulated chondrocytes differentiation process of MSCs $[40,53]$.

\section{Soft tissue sarcomas \\ Synovial sarcoma}

In synovial sarcoma, exogenous expression of SYT-SSX2 fusion gene in the skeletal-muscle-specific Myf5 expressing lineage induced the formation of synovial sarcomas in vivo. Remarkably, when this fusion gene was introduced into cells more differentiated than myoblasts synovial sarcoma did not occur [68]. This fact emphasizes the important role of cell status in the genesis of specific type of sarcomas. On the other hand, fusion gene silencing in primary synovial sarcoma cells restored both the trilineage differentiation capacity and the MSC marker expression, strongly suggesting cells of MSC lineage as the origin of synovial sarcoma [69]. This may be explained by the fact that although considered as muscle specific Myf5 can also be expressed in some MSCs during development.

\section{Other soft tissue sarcomas}

Similar results as described above were seen in a mouse model of liposarcoma, where FUS -CHOP was able to induce liposarcoma genesis in MSCs, whereas no liposarcoma was formed when FUS-CHOP gene was manipulated to be only expressed in differentiated, aP2-expressing adipocytes. This study again underscores the exact cell status as a crucial factor in sarcomagenesis $[42,70]$. However other studies show that there is considerate plasticity in the different lineages since rhadomyosarcoma, an aggressive skeletal muscle tumour can be generated from adipocytes by activation of Sonic Hedgehog signaling [71]. A third soft tissue sarcoma model is that of clear cell sarcoma, characterized by melanoma-like features and an EWSR1/ATF1 translocation. Conditional expression of the human EWSR1/ATF1 fusion gene in mouse gives rise to tumorigenesis with extreme brief latency. The most stem-like MSCs give rise to fully melanoma-like lesions, whereas more differentiated cells result in a less clear cell sarcoma phenotype [72].

\section{Discussion}

Until now there have not been many studies addressing the effect of MSCs of different tissues and different ways of preparation on the role of MSCs as a model for sarcoma genesis. The conspicuous difference between mouse and human MSCs in spontaneous transformation can be possibly explained by many factors. In human cells, the telomeric DNA is often $5-10 \mathrm{~kb}$ long and mouse cells have a telomeric DNA length of 30-40 kb $[41,51]$. The longer telomeres in mouse MSCs allow cells to proliferate many generations before reaching reaching the telomere length limit, giving higher chance for cell to acquire aberrations $[41,51]$. Since mice have a shorter life span than humans, the genome maintenance in mouse cells is also less stringent than in human cells [73].

Niche is one of the most important factors in the determination of stem cell characteristics. The function of niche in stem cell differentiation and pluripotency maintenance is well known. There has also been research showing that the low oxygen tension is important for multipotency maintenance of MSCs, while normal oxygen level will induce differentiation [74]. Besides, niche has also been indicated to be involved in tumorigenesis [75]. This suggests the important role of niche in genomic instability and therefore tumourigenetic ability. One special feature of the bone marrow niche is the partnership of MSCs and haematopoietic stem cells, which deserves further exploration [76,77]. 


\section{Future considerations}

The numerous but well documented studies on MSCs giving rise to sarcomas in experimental set-up provide excellent models to study this devastating malignancy in a systematic and controlled way. This offers opportunities for preclinical testing of experimental therapies, thereby providing convincing data that may facilitate application in actual clinical trials despite small patient cohorts.

\section{Conclusions}

Although mouse MSCs have exhibited definite readiness to transform in vitro, human MSCs do not go through transformation in ex vivo expansion and need additional manipulation before progression into sarcomas. Therefore, although there are few cases of osteosarcoma genesis in patients infused with bone marrow MSCs [45-47], it is considered generally safe to use human MSCs in clinic.

\section{Abbreviations}

AKT: v-akt murine thymoma viral oncogene homolog; AMSC: Adipose tissue derived MSC; APC: Adenomatous polyposis coli; BMI-1: B lymphoma Mo-MLV insertion region 1 homolog; BMMSC: Bone marrow derived MSC; C-myc: vmyc myelocytomatosis viral oncogene; Cdkn2a: Cyclin-dependent kinase inhibitor A; CHOP: C/EBP homologous protein; DKK1: dickkopf 1 homolog; EWS: Ewing Sarcoma; ETS: E-twenty six; FKHR: Forkhead in rhabdomyosarcoma; FLI1: Friend leukemia integration 1; Fos: FBJ murine osteosarcoma viral oncogene; FUS: Fused in sarcoma; H-RAS: v-Ha-ras Harvey rat sarcoma viral oncogene homolog; HLA-DR: Human leukocyte antigen-DR chain; HPV: Human papillomavirus; hTERT: Human telomerase reverse transcriptase; IDH: Isocitrate dehydrogenase; INK4A/ARF: Inhibitor of CDK4 A/ Alternative Reading Frame; K-ras: v-Ki-ras2 Kirsten rat sarcoma viral oncogene homolog; MAPK: Mitogen-activated protein kinase; MSC: Mesenchymal Stem Cell; MYF6: Myogenic factor 6; PAX3/7: Paired box 3/7;

PI3K: Phosphatidylinositol-3-kinase; Prx1: Peroxiredoxin 1; Pten: Phosphatase and tensin homolog; Rb: Retinoblastoma; SSX2: Synovial sarcoma

translocation 2; SV40-LT: Simian virus 40-large antigen; SYT: Synaptotagmin; TERT: Telomerase reverse transcriptase.

\section{Competing interests}

The authors declare that they have no competing interests.

\section{Authors' contributions}

Wei Xiao drafted the manuscript. Alexander B. Mohseny, Anne-Marie CletonJansen and Pancras C. W. Hogendoorn provided comments and suggestions. All authors read and approved the final manuscript.

Received: 22 March 2013 Accepted: 1 July 2013

Published: 23 July 2013

\section{References}

1. Friedenstein AJ, Chailakhjan RK, Lalykina KS: The development of fibroblast colonies in monolayer cultures of guinea-pig bone marrow and spleen cells. Cell Tissue Kinet 1970, 3:393-403.

2. Dominici M, Le Blanc K, Mueller I, Slaper-Cortenbach I, Marini FC, Krause DS, et al: Minimal criteria for defining multipotent mesenchymal stromal cells: the International society for cellular therapy position statement. Cytotherapy 2006, 8:315-317.

3. Mohseny AB, Xiao W, Carvalho R, Spaink HP, Hogendoorn PC, Cleton-Jansen AM: An osteosarcoma zebrafish model implicates Mmp-19 and Ets-1 as well as reduced host immune response in angiogenesis and migration. J Pathol 2012, 227:245-253.

4. Mohseny AB, Szuhai $K$, Romeo S, Buddingh EP, Briaire-De BI, De JD, et al: Osteosarcoma originates from mesenchymal stem cells in consequence of aneuploidization and genomic loss of Cdkn2. J Pathol 2009, 219:294-305.
5. Mohseny $A B$, Hogendoorn PCW: Concise review: mesenchymal tumors: when stem cells go mad. Stem Cells 2011, 29:397-403.

6. Tolar J, Nauta AJ, Osborn MJ, Panoskaltsis MA, McElmurry RT, Bell S, et al: Sarcoma derived from cultured mesenchymal stem cells. Stem Cells 2007, 25:371-379.

7. Chanda D, Kumar S, Ponnazhagan S: Therapeutic potential of adult bone marrow-derived mesenchymal stem cells in diseases of the skeleton. J Cell Biochem 2010, 111:249-257.

8. Rubio R, Garcia-Castro J, Gutierrez-Aranda I, Paramio J, Santos M, Catalina P, et al: Deficiency in p53 but not retinoblastoma induces the transformation of mesenchymal stem cells in vitro and initiates leiomyosarcoma in vivo. Cancer Res 2010, 70:4185-4194.

9. Choumerianou DM, Dimitriou H, Perdikogianni C, Martimianaki G, Riminucci M, Kalmanti M: Study of oncogenic transformation in ex vivo expanded mesenchymal cells, from paediatric bone marrow. Cell Prolif 2008, 41:909-922.

10. Zheng $Y, H e L$, Wan $Y$, Song J: H3K9me-enhanced DNA hypermethylation of the p16(INK4a) gene: an epigenetic signature for spontaneous transformation of rat mesenchymal stem cells. Stem Cells Dev 2013, 22:256-267.

11. Rodriguez R, Rubio R, Gutierrez-Aranda I, Melen GJ, Elosua C, Garcia-Castro J, et al: FUS-CHOP fusion protein expression coupled to p53 deficiency induces liposarcoma in mouse but not in human adipose-derived mesenchymal stem/stromal cells. Stem Cells 2011, 29:179-192.

12. Aguilar S, Nye E, Chan J, Loebinger M, Spencer-Dene B, Fisk N, et al: Murine but not human mesenchymal stem cells generate osteosarcoma-like lesions in the lung. Stem Cells 2007, 25:1586-1594.

13. Rosland GV, Svendsen A, Torsvik A, Sobala E, McCormack E, Immervoll H, et al: Long-term cultures of bone marrow-derived human mesenchymal stem cells frequently undergo spontaneous malignant transformation. Cancer Res 2009, 69:5331-5339.

14. Rodriguez R, Rubio R, Menendez P: Modeling sarcomagenesis using multipotent mesenchymal stem cells. Cell Res 2012, 22:62-77.

15. Bernardo ME, Zaffaroni N, Novara F, Cometa AM, Avanzini MA, Moretta A, et al: Human bone marrow derived mesenchymal stem cells do not undergo transformation after long-term in vitro culture and do not exhibit telomere maintenance mechanisms. Cancer Res 2007, 67:9142-9149.

16. Shimizu T, Ishikawa T, Sugihara E, Kuninaka S, Miyamoto T, Mabuchi Y, et al: c-MYC overexpression with loss of Ink4a/Arf transforms bone marrow stromal cells into osteosarcoma accompanied by loss of adipogenesis. Oncogene 2010, 29:5687-5699.

17. Lin PP, Pandey MK, Jin FH, Raymond AK, Akiyama H, Lozano G: Targeted mutation of $\mathrm{p} 53$ and $\mathrm{Rb}$ in mesenchymal cells of the limb bud produces sarcomas in mice. Carcinogenesis 2009, 30:1789-1795.

18. Sandberg AA, Bridge JA: Updates on the cytogenetics and molecular genetics of bone and soft tissue tumors: osteosarcoma and related tumors. Cancer Genet Cytogenet 2003, 145:1-30.

19. Zhou YF, Bosch-Marce M, Okuyama H, Krishnamachary B, Kimura H, Zhang $L$, et al: Spontaneous transformation of cultured mouse bone marrowderived stromal cells. Cancer Res 2006, 66:10849-10854.

20. Xu S, De BA, De RH, Van CB, Vanderkerken K, Van R: I: In vitro expanded bone marrow-derived murine (C57BI/KaLwRij) mesenchymal stem cells can acquire CD34 expression and induce sarcoma formation in vivo. Biochem Biophys Res Commun 2012, 424:391-397.

21. Charbord P: Bone marrow mesenchymal stem cells: historical overview and concepts. Hum Gene Ther 2010, 21:1045-1056.

22. Li Q, Hisha H, Takaki T, Adachi Y, Li M, Song C, et al: Transformation potential of bone marrow stromal cells into undifferentiated high-grade pleomorphic sarcoma. J Cancer Res Clin Oncol 2010, 136:829-838.

23. Josse C, Schoemans R, Niessen NA, Delgaudine M, Hellin AC, Herens C, et al: Systematic chromosomal aberrations found in murine bone marrowderived mesenchymal stem cells. Stem Cells Dev 2010, 19:1167-1173.

24. Rodriguez R, Rubio R, Masip M, Catalina P, Nieto A, De la Cueva T, et al: Loss of p53 induces tumorigenesis in p21-deficient mesenchymal stem cells. Neoplasia 2009, 11:397-U106.

25. Li H, Fan X, Kovi RC, Jo Y, Moquin B, Konz R, et al: Spontaneous expression of embryonic factors and p53 point mutations in aged mesenchymal stem cells: a model of age-related tumorigenesis in mice. Cancer Res 2007, 67:10889-10898.

26. Ruther U, Komitowski D, Schubert FR, Wagner EF: c-fos expression induces bone tumors in transgenic mice. Oncogene 1989, 4:861-865. 
27. Amary MF, Bacsi K, Maggiani F, Damato S, Halai D, Berisha F, et al: IDH1 and $\mathrm{IDH} 2$ mutations are frequent events in central chondrosarcoma and central and periosteal chondromas but not in other mesenchymal tumours. J Pathol 2011, 224:334-343.

28. de Andrea CE, Reijnders CM, Kroon HM, De JD, Hogendoorn PC, Szuhai K, et al: Secondary peripheral chondrosarcoma evolving from osteochondroma as a result of outgrowth of cells with functional EXT. Oncogene 2012, 31:1095-1104.

29. Bovee JV, Hogendoorn PC, Wunder JS, Alman BA: Cartilage tumours and bone development: molecular pathology and possible therapeutic targets. Nat Rev Cancer 2010, 10:481-488.

30. Hernando E, Charytonowicz E, Dudas ME, Menendez S, Matushansky I, Mills J, et al: The AKT-mTOR pathway plays a critical role in the development of leiomyosarcomas. Nat Med 2007, 13:748-753.

31. Engelman JA: Targeting PI3K signalling in cancer: opportunities, challenges and limitations. Nat Rev Cancer 2009, 9:550-562.

32. Tsumura H, Yoshida T, Saito H, Imanaka-Yoshida K, Suzuki N: Cooperation of oncogenic K-ras and p53 deficiency in pleomorphic rhabdomyosarcoma development in adult mice. Oncogene 2006, 25:7673-7679.

33. Kirsch DG, Dinulescu DM, Miller JB, Grimm J, Santiago PM, Young NP, et al: A spatially and temporally restricted mouse model of soft tissue sarcoma. Nat Med 2007, 13:992-997.

34. Rubio D, Garcia-Castro J, Martin MC, de la Fuente R, Cigudosa JC, Lloyd AC, et al: Spontaneous human adult stem cell transformation. Cancer Res 2005, 65:3035-3039.

35. de la Fuente R, Bernad A, Garcia-Castro J, Martin MC, Cigudosa JC: Spontaneous human adult stem cell transformation (retraction of vol 65, pg 3035, 2005). Cancer Res 2010, 70:6682.

36. Fletcher CDM, Unni K, Mertens F: Pathology and Genetics of Tumours of Soft Tissue and Bone. Lyon: IARCPress; 2002:264-270.

37. Mirabello L, Troisi RJ, Savage SA: Osteosarcoma incidence and survival rates from 1973 to 2004: data from the surveillance, epidemiology, and end results program. Cancer 2009, 115:1531-1543

38. Li N, Yang R, Zhang W, Dorfman H, Rao P, Gorlick R: Genetically transforming human mesenchymal stem cells to sarcomas: changes in cellular phenotype and multilineage differentiation potential. Cancer 2009, 115:4795-4806.

39. Tang N, Song WX, Luo J, Haydon RC, He TC: Osteosarcoma development and stem cell differentiation. Clin Orthop Relat Res 2008, 466:2114-2130

40. de Andrea CE, Hogendoorn PCW: Epiphyseal growth plate and secondary peripheral chondrosarcoma: the neighbours matter. J Pathol 2012, 226:219-228.

41. Smogorzewska A, de Lange T: Different telomere damage signaling pathways in human and mouse cells. EMBO J 2002, 21:4338-4348.

42. Perez-Losada J, Sanchez-Martin M, Rodriguez-Garcia MA, Perez-Mancera PA, Pintado B, Flores T, et al: Liposarcoma initiated by FUS/TLS-CHOP: the FUS/TLS domain plays a critical pole in the pathogenesis of liposarcoma. Oncogene 2000, 19:6015-6022.

43. Wang Y, Huso DL, Harrington J, Kellner J, Jeong DK, Turney J, et al: Outgrowth of a transformed cell population derived from normal human BM mesenchymal stem cell culture. Cytotherapy 2005, 7:509-519.

44. Torsvik A, Rosland GV, Svendsen A, Molven A, Immervoll H, McCormack E, et al: Spontaneous malignant transformation of human mesenchymal stem cells reflects cross-contamination: putting the research field on track - letter. Cancer Res 2010, 70:6393-6396.

45. Berger M, Muraro M, Fagioli F, Ferrari S: Osteosarcoma derived from donor stem cells carrying the Norrie's disease gene. N Engl J Med 2008, 359:2502-2504.

46. Bielack SS, Rerin JS, Dickerhoff R, Dilloo D, Kremens B, Von SA, et al: Osteosarcoma after allogeneic bone marrow transplantation: a report of four cases from the cooperative osteosarcoma study group (COSS). Bone Marrow Transplant 2003, 31:353-359.

47. Amariglio N, Hirshberg A, Scheithauer BW, Cohen Y, Loewenthal R, Trakhtenbrot $L$, et al: Donor-derived brain tumor following neural stem cell transplantation in an ataxia telangiectasia patient. PLoS Med 2009, 6:e1000029

48. Serakinci N, Guldberg P, Burns JS, Abdallah B, Schrodder $H$, Jensen T, et al: Adult human mesenchymal stem cell as a target for neoplastic transformation. Oncogene 2004, 23:5095-5098.
49. Shima $Y$, Okamoto T, Aoyama T, Yasura $K$, Ishibe $T$, Nishijo $K$, et al: In vitro transformation of mesenchymal stem cells by oncogenic H-ras(Val12). Biochem Biophys Res Commun 2007, 353:60-66.

50. Funes JM, Quintero M, Henderson S, Martinez D, Qureshi U, Westwood C, et al: Transformation of human mesenchymal stem cells increases their dependency on oxidative phosphorylation for energy production. PNAS 2007, 104:6223-6228.

51. Weinberg RA: Eternal life: cell immortalization and tumorigenesis. In the biology of cancer. Garland Science; 2007:357-398.

52. Tirode F, Laud-Duval K, Prieur A, Delorme B, Charbord P, Delattre O: Mesenchymal stem cell features of Ewing tumors. Cancer Cell 2007, 11:421-429.

53. Boeuf S, Kunz P, Hennig T, Lehner B, Hogendoorn P, Bovee J, et al A chondrogenic gene expression signature in mesenchymal stem cells is a classifier of conventional central chondrosarcoma. J Pathol 2008, 216:158-166.

54. Matushansky I, Hernando E, Socci ND, Mills JE, Matos TA, Edgar MA, et al: Derivation of sarcomas from mesenchymal stem cells via inactivation of the Wnt pathway. J Clin Invest 2007, 117:3248-3257.

55. Helman LJ, Meltzer P: Mechanisms of sarcoma development. Nat Rev Cancer 2003, 3:685-694.

56. Berman SD, Calo E, Landman AS, Danielian PS, Miller ES, West JC, et al: Metastatic osteosarcoma induced by inactivation of Rb and $\mathrm{p} 53$ in the osteoblast lineage. PNAS 2008, 105:11851-11856.

57. Walkley CR, Qudsi R, Sankaran VG, Perry JA, Gostissa M, Roth SI, et al: Conditional mouse osteosarcoma, dependent on p53 loss and potentiated by loss of Rb, mimics the human disease. Genes Dev 2008, 22:1662-1676.

58. Miura M, Miura Y, Padilla-Nash HM, Molinolo AA, Fu B, Patel V, et al: Accumulated chromosomal instability in murine bone marrow mesenchymal stem cells leads to malignant transformation. Stem Cells 2006, 24:1095-1103.

59. Maheshwari AV, Cheng EY: Ewing sarcoma family of tumors. J Am Acad Orthop Surg 2010, 18:94-107.

60. Riggi N, Cironi L, Suva ML, Stamenkovic I: Sarcomas: genetics, signalling, and cellular origins. Part 1: the fellowship of TET. J Pathol 2007, 213:4-20.

61. Italiano A, Sung YS, Zhang L, Singer S, Maki RG, Coindre JM, et al: High prevalence of $\mathrm{CIC}$ fusion with double-homeobox (DUX4) transcription factors in EWSR1-negative undifferentiated small blue round cell sarcomas. Genes Chromosomes Cancer 2012, 51:207-218.

62. Szuhai K, ljszenga M, De JD, Karseladze A, Tanke HJ, Hogendoorn PC: The NFATc2 gene is involved in a novel cloned translocation in a Ewing sarcoma variant that couples its function in immunology to oncology. Clin Cancer Res 2009, 15:2259-2268.

63. Yeny CT, Eliazer S, Xiang LL, Richardson JA, Ilaria RL: Expression of the EWS/FLI-1 oncogene in murine primary bone-derived cells results in EWS/FLI-1-dependent, Ewing sarcoma-like tumors. Cancer Res 2005, 65:8698-8705

64. Riggi N, Cironi L, Provero P, Suva ML, Kaloulis K, Garcia-Echeverria C, et al: Development of Ewing's sarcoma from primary bone marrow-derived mesenchymal progenitor cells. Cancer Res 2005, 65:11459-11468.

65. Miyagawa $Y$, Okita H, Nakaijima H, Horiuchi $Y$, Sato B, Taguchi $T$, et al: Inducible expression of chimeric EWS/ETS proteins confers Ewing's family tumor-like phenotypes to human mesenchymal progenitor cells. Mol Cell Biol 2008, 28:2125-2137.

66. Lin PP, Pandey MK, Jin FH, Xiong SB, Deavers N, Parant JM, et al: EWS-FLI1 induces developmental abnormalities and accelerates sarcoma formation in a transgenic mouse model. Cancer Res 2008, 68:8968-8975.

67. Carvajal $R$, Meyers P: Ewing's sarcoma and primitive neuroectodermal family of tumors. Hematol Oncol Clin North Am 2005, 19:501. vii.

68. Haldar M, Hancock JD, Coffin CM, Lessnick SL, Capecchi MR: A conditional mouse model of synovial sarcoma: insights into a myogenic origin. Cancer Cell 2007, 11:375-388.

69. Naka N, Takenaka S, Araki N, Miwa T, Hashimoto N, Yoshioka K, et al: Synovial sarcoma is a stem cell malignancy. Stem Cells 2010, 28:1119-1131.

70. Perez-Mancera PA, Bermejo-Rodriguez C, Sanchez-Martin M, Abollo-Jimenez F, Pintado B, Sanchez-Garcia I: FUS-DDIT3 prevents the development of adipocytic precursors in liposarcoma by repressing PPAR gamma and C/EBP alpha and activating elF4E. PLoS One 2008, 3:e2569. 
71. Hatley ME, Tang W, Garcia MR, Finkelstein D, Millay DP, Liu N, et al: A mouse model of rhabdomyosarcoma originating from the adipocyte lineage. Cancer Cell 2012, 22:536-546.

72. Straessler KM, Jones KB, Hu H, Jin H, van de Rijn M, Capecchi MR: Modeling clear cell sarcomagenesis in the mouse: cell of origin differentiation state impacts tumor characteristics. Cancer Cell 2013, 23:215-227.

73. Vijg J, Suh Y: Genome instability and aging. Annu Rev Physiol 2013, 75:645-668.

74. Berniakovich I, Giorgio M: Low oxygen tension maintains multipotency, whereas normoxia increases differentiation of mouse bone marrow stromal cells. Int J Mol Sci 2013, 14:2119-2134.

75. Korbut E, Ptak-Belowska A, Brzozowski T: Mechanisms promoting physiological cells progression into tumorigenesis. J Physiol Pharmacol 2012, 63:565-570.

76. Ehninger A, Trumpp A: The bone marrow stem cell niche grows up: mesenchymal stem cells and macrophages move in. J Exp Med 2011, 208:421-428.

77. Mendez-Ferrer S, Michurina TV, Ferraro F, Mazloom AR, Macarthur BD, Lira $S A$, et al: Mesenchymal and haematopoietic stem cells form a unique bone marrow niche. Nature 2010, 466:829-834.

doi:10.1186/2045-3329-3-10

Cite this article as: Xiao et al:: Mesenchymal stem cell transformation and sarcoma genesis. Clinical Sarcoma Research 2013 3:10.

\section{Submit your next manuscript to BioMed Central and take full advantage of:}

- Convenient online submission

- Thorough peer review

- No space constraints or color figure charges

- Immediate publication on acceptance

- Inclusion in PubMed, CAS, Scopus and Google Scholar

- Research which is freely available for redistribution 